\title{
Potential for analytic breeding in allopolyploids: an illustration from Longiflorum $\times$ Asiatic hybrid lilies (Lilium)
}

\author{
Nadeem Khan · Shujun Zhou • M. S. Ramanna \\ Paul Arens · Jeronimo Herrera • \\ Richard G. F. Visser · Jaap M. Van Tuyl
}

Received: 2 June 2008 / Accepted: 18 September 2008 / Published online: 10 October 2008

(C) The Author(s) 2008. This article is published with open access at Springerlink.com

\begin{abstract}
Ploidy level and intergenomic recombination was studied in interspecific hybrids between Longiflorum $\times$ Asiatic lilies (LA hybrid) backcross to Asiatic parents in order to assess the possibility for analytic breeding in lily. By backcrossing the diploid $(2 n=2 x=24)$ F1 interspecific hybrid between Longiflorum $\times$ Asiatic lilies to Asiatic parents, $104 \mathrm{BC} 1$ progeny plants were produced. Among these, there were 27 diploids, 73 triploids $(2 n=2 x=$ 36) and 4 aneuploids $(2 x-1,2 x+2$ or $2 x+3)$. In addition, by backcrossing triploid BC1 (LAA) plants to diploid Asiatic parents in $2 x-3 x$ and reciprocal combinations, 14 diploid $\mathrm{BC} 2$ progenies were produced. Genomic in situ hybridization (GISH) was performed to study the intergenomic recombination and karyotype composition. GISH indicated extensive intergenomic recombination among the chromosomes in LA hybrids. A large number of Longiflorum chromosomes were transmitted to the $\mathrm{BC} 1$ progenies from LA hybrids. However, very few Longiflorum chromosomes were transmitted from the $\mathrm{BC} 1$ triploid
\end{abstract}

N. Khan $(\bowtie) \cdot$ M. S. Ramanna $\cdot$ P. Arens $\cdot$ J. Herrera

R. G. F. Visser · J. M. Van Tuyl

Plant Breeding, Wageningen University and Research,

P.O. Box 16, 6700AA Wageningen, The Netherlands

e-mail: nadeem.khan@wur.nl; khan_m_nadeem@yahoo.com

\section{S. Zhou}

Department of Horticulture, Agricultural and

Technological College, Zhejiang University,

No. 258 KaiXuan Road, Hangzhou City,

Zhejiang Province 310029, China
(LAA) plants to the $\mathrm{BC} 2$ progenies. The occurrence of diploid plants in the $\mathrm{BC}$ progenies of LA hybrids has opened the prospects of analytic breeding in lilies. In this approach, the selection of superior genotypes can be carried out at the diploid level and polyploid forms are synthesized from superior diploid parents. The advantages of analytic breeding are evident: (a) a maximum level of heterozygosity can be attained in the synthetic polyploids and (b) introgression can be achieved with a minimum of linkage drag. Based on GISH results the potential application of analytic breeding in lily allopolyploids has been discussed.

Keywords Back cross progenies - Haploid gametes GISH · Intergenomic recombination · Lily ·

Polyploids

\section{Introduction}

Generally, it is difficult to breed polyploid crops as compared to diploid forms. This is true for both autoand allopolyploids for different reasons. Autopolyploids display polysomic inheritance, the segregation of characters is not clear cut and this complicates the process of selection for desirable combinations of traits (Peloquin 1981). On the other hand, allopolyploids which are also called functional diploids, behave as "permanent hybrids" because of the preferential chromosome pairing between the parental genomes during meiosis (Barba-Gonzalez et al. 2005; Feldman 
and Levy 2005). As a result, hardly any genetic variation occurs in the progenies of allopolyploids due to fixed heterozygosity and this is not favourable for the process of selection. In view of these differences, auto- and allopolyploids require different breeding approaches.

For autopolyploids, Chase (1963) proposed a novel approach, the so called "analytic breeding", which was applied in the case of cultivated potato, Solanum tuberosum L. (Mendiburu et al. 1974). This approach involves the reduction of tetraploids to diploid level followed by intensive selection of superior genotypes through breeding at this level and in the final step tetraploid cultivars are produced (through sexual polyploidization) from the selected diploid parents (Jacobsen et al. 1991). Many practical advantages of breeding at the diploid level, such as relatively simple Mendelian segregation of characters and the requirement of smaller size of population for selection, have been highlighted along with other theoretical considerations (Bingham et al. 1994). Analytic breeding has also been relevant in other crops like alfalfa (Mariani and Tavoletti 1992; Barcaccia et al. 2000) and cranberry (Lyrene et al. 2003; Zeldin and McCown 2004). In view of the attractiveness of analytic breeding in autopolyploids, the question arises whether such an approach can also be relevant for breeding allopolyploids.

Breeding at the diploid level implies that the genotypes used in this approach necessarily produce haploid ( $n$ ) gametes so that they give rise to diploids in the subsequent generations (Zeldin and McCown 2004). In the hybrids of species that possess very closely related or similar genomes (the case for autopolyploids) it is not a problem to have diploid forms that can produce functional $n$ gametes due to normal segregation of chromosomes during meiosis (Weiss and Maluszynska 2000; Lopez-Lavalle and Orjeda 2002; Gu et al. 2005; Hoya et al. 2007; Zhang et al. 2007). On the contrary, in interspecific hybrids of distantly related species (allopolyploid types) it is very difficult to have genotypes that can produce normal $n$ gametes. This is because such diploid hybrids are mostly sterile due to a disturbed segregation of chromosomes during meiosis (Estilai 1977; Van Tuyl and De Jeu 1997; Lim et al. 2000; Barba-Gonzalez et al. 2006b). However, if diploid (distant) interspecific hybrids that can produce both $n$ as well as $2 n$ gametes become available, there might be a potential for analytic breeding even in the case of allopolyploids. Once the selection has been made at the diploid level, then the unilateral sexual polyploids can be achieved by using $2 n$ gametes to reach the optimum ploidy level, e.g., triploid in lilies (Van Tuyl and Lim 2003; Zhou et al. 2008). Hence, the analytic breeding scheme might be possible when genotypes producing both $n$ and $2 n$ gametes are available. The cultivated lilies appear to possess such a potential. There are three important groups of cultivated lilies (Lilium), viz., Longiflorum, Asiatic and Oriental, which were predominantly diploid $(2 n=2 x=24)$ until recently (Lim et al. 2000). During the last few decades, polyploids have been replacing the diploid forms due to their superior characteristics of the former. These polyploid cultivars have originated from hybridization of cultivars that belong to different taxonomic sections of lilies such as Longiflorum $\times$ Asiatic (LA) [Lim et al. 2001; Zhou et al. 2008] or Oriental $\times$ Asiatic (OA) [Barba-Gonzalez et al. 2004; 2005]. Because the three groups possess clearly differentiated genomes, their hybrids have given rise to typical allotriploid (ALA and AOA) or allotetraploid (LLAA) cultivars (Barba-Gonzalez et al. 2005; Zhou 2007; Zhou et al. 2008). These polyploids are difficult to use as parents in breeding because the triploids are mostly sterile and the allotetraploids are permanent hybrids as was mentioned earlier. A salient feature of some of the diploid LA hybrids was that they produced not only $2 n$ gametes but also $n$ gametes (Zhou 2007). This provides unique opportunities for generating allotriploid $(2 n=3 x=36)$ as well as diploid $(2 n=2 x=24)$ BC1 progenies from backcrossing LA hybrids to Asiatic parents. In addition, diploid BC2 progenies were also generated from backcrossing allotriploid (ALA or LAA) to diploid Asiatic parents, i.e., $3 x-2 x$ or reciprocal crosses. These initial attempts indicated that it might be possible to generate fairly large numbers of diploid $\mathrm{BC} 1$ and $\mathrm{BC} 2$ progenies from LA hybrids and their backcross progenies. With the aim of evaluating the prospects of using diploid backcross progenies in analytic breeding, quite a number of diploid BC progenies from LA hybrids were produced and the genome composition of the diploid $\mathrm{BC} 1$ and $\mathrm{BC} 2$ progenies were analysed by GISH. Based on these results the potential application and significance of these hybrids is discussed with particular reference to analytic breeding in allopolyploids lilies. 


\section{Materials and methods}

Plant material

Most of the diploid F1 Longiflorum $\times$ Asiatic hybrids ( $2 n=2 x=24)$, and allotriploids i.e., LAA and ALA $(2 n=3 x=36)$ cultivars were supplied by Dutch lily breeding companies: De Jong Lilies BV, Royal Van Zanten BV, Testcentrum BV, Vletter and Den Haan BV and World Breeding BV. One F1 LA hybrids i.e., 024004-5 was developed at Plant Breeding, Wageningen UR. As the two groups which belong to two different taxonomic sections, the cultivars of different sections could be hybridized, or backcrossed, only through special techniques (Van Tuyl et al. 1991; Lim et al. 2001; Barba-Gonzalez et al. 2004). For backcrossing, the F1 LA hybrids were used both as female and male parent and crossed with eight different Asiatic parents to get LAA or ALA progenies (Table 1). Furthermore, the triploid genotypes from the breeders (which were $\mathrm{BC} 1 \mathrm{~s}$ ) were backcrossed to diploid Asiatic parents by using both $2 x-3 x$ or reciprocal combinations (Table 2). All the plant material is being maintained vegetatively at Wageningen UR, Plant Breeding, Wageningen, The Netherlands.

Pollen germination

Pollen was collected on day of anthesis and cultured for $5-20 \mathrm{~h}$ at $25^{\circ} \mathrm{C}$ in an artificial agar medium containing $100 \mathrm{~g} / \mathrm{l}$ sucrose, $5 \mathrm{~g} / \mathrm{l}$ of bacteriological agar, $20 \mathrm{mg} / \mathrm{l}$ of boric acid and $200 \mathrm{mg} / \mathrm{l}$ of calcium nitrate. The percentage of germinating pollen was determined based on the growth of pollen tube under an anatomical microscope.

Flow cytometry

Flow cytometry was done to evaluate the ploidy level of the $\mathrm{BC} 1$ and $\mathrm{BC} 2$ progenies. The germinating embryos were transferred into the propagation medium and allowed to grow until leaves developed. One leaf or scale was collected from each seedling for testing ploidy level as described by Van Tuyl and Boon (1997).

\section{Mitotic chromosome preparation}

For mitotic metaphase chromosome analysis, root tips were collected early in the morning, incubated in
$0.7 \mathrm{mM}$ cycloheximide solution for $4-6 \mathrm{~h}$ and then fixed in ethanol-acetic acid (3:1) solution for 12-24 h and stored at $4{ }^{\circ} \mathrm{C}$ until use. The root tips were washed in distilled water and incubated in a pectolytic enzyme mixture containing $0.2 \%(\mathrm{w} / \mathrm{v})$ pectyolase $\mathrm{Y} 23,0.2 \%$ $(\mathrm{w} / \mathrm{v})$ cytohelicase and $0.2 \%(\mathrm{w} / \mathrm{v})$ cellulase RS in $10 \mathrm{mM}$ citrate buffer $(\mathrm{pH} 4.5)$ at $37^{\circ} \mathrm{C}$ for about $1 \mathrm{~h}$. Squash preparations were made in a drop of $45 \%$ acetic acid and frozen in liquid nitrogen. The cover slips were removed by using a razor blade. The slides were then dehydrated in absolute ethanol and air dried.

\section{Genomic in situ hybridization (GISH)}

Genomic DNA of Longiflorum cultivar 'White Fox' was used as probe in GISH and labelled with Digoxigenin-11-dUTP by nick translation (Roche Diagnostics $\mathrm{GmbH}$, Mannheim, Germany). The GISH procedure was performed as described by Lim et al. (2003) and Zhou et al. (2008). Briefly, the hybridization mixture contained $50 \%(\mathrm{v} / \mathrm{v})$ deionized formamide, $10 \%(\mathrm{w} / \mathrm{v})$ sodium dextran sulphate, $2 \times \mathrm{SSC}, 0.25 \%(\mathrm{w} / \mathrm{v})$ sodium dodecyl sulphate, $1-1.5 \mathrm{ng} / \mu \mathrm{l}$ Digoxigenin labelled DNA from Longiflorum cultivars and 25-100 ng/ $\mu$ l block DNA of the Asiatic cultivar. DNA was denatured by heating the hybridization mixture at $70^{\circ} \mathrm{C}$ for $10 \mathrm{~min}$ followed by incubation in ice for $5 \mathrm{~min}$. The hybridization mixture $(40 \mu \mathrm{l})$ was then applied on each slide. The chromosome preparations were denatured at $80^{\circ} \mathrm{C}$ for 5 min immediately prior to incubation. After overnight hybridization in a humid chamber at $37^{\circ} \mathrm{C}$ the slides were washed at room temperature in $2 \times \mathrm{SSC}$ for $15 \mathrm{~min}$ followed by stringent washing with $0.1 \times \mathrm{SSC}$ for $30 \mathrm{~min}$ at $42^{\circ} \mathrm{C}$. Digoxigenin labelled DNA was detected with antidigoxigenin-fluorescein raised in sheep (Boehringer, Mannheim, Germany) and amplified with fluorescein anti-sheep immunoglobulin raised in rabbit (Vector Laboratories). Preparations were analysed using a Zeiss Axiophot epifluorescence microscope and photographed by Canon digital camera. For each plant, the total number of chromosomes and the number of recombinant points were determined.

Chromosome identification, measurement and determination of genome contribution

For karyotyping in both genomes ( $\mathrm{L}$ and A), chromosomes are arranged in sequence of decreasing short-arm 
Table 1 The frequencies of diploid $(2 n=2 x=24)$, or aneuploid, and triploid $(2 n=3 x=36)$ BC1 progenies resulting from crosses between different genotypes of LA hybrids and the Asiatic parents

\begin{tabular}{|c|c|c|c|c|c|c|c|}
\hline \multirow[t]{2}{*}{ Cross } & \multirow{2}{*}{$\begin{array}{l}\text { Genotype } \\
\text { code }\end{array}$} & \multicolumn{2}{|l|}{ Parents } & \multirow{2}{*}{$\begin{array}{l}\text { No. of plants } \\
\text { analysed }\end{array}$} & \multicolumn{3}{|c|}{ Ploidy level $^{\mathrm{b}}$} \\
\hline & & Female & Male & & $2 x$ & $3 x$ & Others \\
\hline LAA & 044511 & 041543 & Mont Blanc & 2 & 2 & & \\
\hline $\mathrm{LAA}^{\mathrm{a}}$ & 044512 & 041558 & Mont Blanc & 1 & & 1 & \\
\hline LAA & 044518 & 041543 & Pollyanna & 1 & & 1 & \\
\hline LAA & 044525 & 041556 & Mont Blanc & 1 & & 1 & \\
\hline LAA & 044535 & 041562 & Pollyanna & 1 & & 1 & \\
\hline LAA & 044536 & 041563 & Pollyanna & 1 & 1 & & \\
\hline LAA & 044538 & 041560 & Pollyanna & 4 & 4 & & \\
\hline LAA & 044539 & 041558 & Pollyanna & 5 & & 5 & \\
\hline LAA & 044541 & 041549 & Pollyanna & 1 & & 1 & \\
\hline LAA & 044567 & 041548 & Pollyanna & 1 & & 1 & \\
\hline LAA & 044571 & 041557 & Mont Blanc & 4 & & 4 & \\
\hline LAA & 044611 & 041559 & Pollyanna & 1 & & 1 & \\
\hline LAA & 044624 & 041565 & Pollyanna & 1 & & 1 & \\
\hline LAA & 044630 & 041502 & Mont Blanc & 1 & & 1 & \\
\hline LAA & 062035 & 041560 & Sarina & 2 & & 2 & \\
\hline LAA & 062071 & 041560 & Montreux & 4 & 1 & 3 & \\
\hline LAA & 062074 & 041560 & Montreux & 5 & 2 & 3 & \\
\hline LAA & 065051 & $024004-5$ & 061095 & 4 & 2 & 1 & $1(2 x-1)$ \\
\hline LAA & 066828 & 041543 & 051072 & 5 & 1 & 4 & \\
\hline LAA & 066960 & 041543 & Lanzarote & 18 & 3 & 14 & $1(2 x+2)$ \\
\hline LAA & 066963 & 041543 & Gironde & 7 & 2 & 5 & \\
\hline LAA & 066994 & 041560 & Alaska & 13 & 6 & 5 & $2(2 x+3)$ \\
\hline LAA & 066995 & 041560 & 031040 & 1 & & 1 & \\
\hline $\mathrm{ALA}^{\mathrm{a}}$ & 044595 & Pollyanna & 041519 & 3 & 1 & 2 & \\
\hline ALA & 044601 & Mont Blanc & 041502 & 9 & & 9 & \\
\hline ALA & 044602 & Mont Blanc & 041557 & 2 & 2 & & \\
\hline ALA & 044608 & Vivaldi & 041502 & 6 & & 6 & \\
\hline Total & & & & 104 & 27 & 73 & 4 \\
\hline
\end{tabular}

${ }^{a}$ Denotes only the direction of the crosses but not the ploidy level. LAA indicates that the hybrid LA was the female parent and ALA indicates that LA hybrid was the male parent

b Estimated cytologically

length according to Stewart (1947). Some of the chromosomes in the somatic karyotype could be identified on the basis of total length and arm ratios (e.g., 1, 2, 3 10, 11 and 12). In other cases, however, the differences in the lengths of short-arms were used for identification. By identifying recombination sites analysed by GISH, the same chromosome could be accurately identified in 5-10 cells and compared with the previous and the succeeding chromosomes in the karyotype. Furthermore, the centromeric index (short-arm length/short-arm length + long-arm length) and the relative chromosome length index (individual chromosome length/total length of all chromosomes) were determined for all genotypes (Barthes and Ricroch 2001). For the measurements and determination of genome contribution, images of mitotic metaphase chromosomes from each genotype were collected and were measured in micrometres $(\mu \mathrm{m})$. The contribution of the amount of both $\mathrm{L}$ and A genomes (in terms of percentage) in BC progenies was determined using the computer programme MicroMeasure (Reeves and Tear 2000; http://www. colostate.edu/Depts/Biology/MicroMeasure). 
Table 2 The ploidy level of BC2 progenies resulting from crossing triploid BC1 plants with diploid Asiatic parents

\begin{tabular}{|c|c|c|c|c|}
\hline \multirow[t]{2}{*}{ Interploid crosses } & \multicolumn{2}{|l|}{ Parents } & \multirow{2}{*}{$\begin{array}{l}\text { No. of plants } \\
\text { analysed }\end{array}$} & \multirow{2}{*}{$\begin{array}{l}\text { No. of diploid } \\
\text { plants }^{\text {a }}\end{array}$} \\
\hline & Female & Male & & \\
\hline \multicolumn{5}{|l|}{$2 x-3 x(\mathrm{BC} 2)$} \\
\hline 044529 & Pollyanna & 041513 & 3 & 3 \\
\hline 044530 & Mont Blanc & 041513 & 5 & 5 \\
\hline \multicolumn{5}{|l|}{$3 x-2 x(\mathrm{BC} 2)$} \\
\hline 044519 & 041513 & Pollyanna & 3 & 3 \\
\hline 044524 & 041513 & Mont Blanc & 1 & 1 \\
\hline 044634 & 041552 & Pollyanna & 3 & 2 \\
\hline Total & & & 15 & 14 \\
\hline
\end{tabular}

a Estimated cytologically

\section{Results}

Production of $\mathrm{BC} 1$ and $\mathrm{BC} 2$ progenies from $\mathrm{LA}$ hybrids

In order to assess the possibility to produce relatively large number of diploid backcross progenies from the LA hybrids or from its $\mathrm{BC} 1$ progenies a large number of crosses were made. For this purpose, several LA hybrids and allotriploid BC1 (LAA) genotypes were backcrossed to diploid Asiatic parents and the ploidy levels of these progenies were determined through flow cytometry (data not presented) as well as by cytological chromosome counting (Tables 1 and 2).

Not all LA hybrids were successful as male and female parents. Viable pollen grains (5-30\%) were produced in some cases (e.g., F1 hybrids 041502, 041519, 041557) and these could be used successfully as male parents (Table 1). Other genotypes could only be used as female parent. By crossing LA hybrids both as female and male parent, a total of $104 \mathrm{BC} 1$ progenies were obtained of which 27 (26\%) were diploid, $73(70.2 \%)$ were triploid and four were aneuploid (3.8\%) with $2 x-1,2 x+2$ and $2 x+3$, respectively. This indicated the occurrence of haploid $(n)$, diploid $(2 n)$ and aneuploid gametes in the LA hybrids (Table 1). Analysis of the different BC1 types produced by each genotype indicated that three genotypes produced only $n$ eggs. All other produced both $n$ and $2 n$ eggs although in the majority of cases $2 n$ eggs are produced. Similarly, there was one genotype that produced only $n$ pollen (041557), one that produced both $n$ and $2 n$ pollen (041519) and one genotype produced only $2 n$ pollen (041502). The observations indicated that it was possible to produce reasonable numbers of diploid $\mathrm{BC} 1$ progenies along with a large number of triploid progenies from LA hybrids despite possessing highly differentiated genomes and abnormal meiosis in these hybrids.

Apart from producing $\mathrm{BC} 1$ progenies from diploid LA hybrids, an attempt was also made to obtain diploid progenies by backcrossing allotriploid (LAA and ALA) BC1 plants with different diploid Asiatic parents. From the flow cytometric determination of the ploidy levels of the progenies of $2 x-3 x$ and reciprocal crosses, it was established that $90.33 \%$ of the BC2 plants showed diploid chromosome numbers and this was confirmed cytologically (Table 2; Fig. 1c). Obviously, despite being allotriploids, they produced balanced haploid gametes both male and female, giving rise to diploid $\mathrm{BC} 2$ progenies on back crossing.

Genome composition and the extent of crossing-over in $\mathrm{BC}$ progenies

Through GISH analysis, the genome composition was determined in 24 diploid BC1 (Table 3) and five BC2 plants (Table 4). Among BC1 progenies, 20 had the expected 24 chromosomes and four were aneuploid $(2 x-1,2 x+2$ or $2 x+3)$. Because the Asiatic parent was used for backcrossing, the number of A genome chromosomes (chromosomes of which the centromere was of Asiatic genome) predominated in the $\mathrm{BC} 1$ progenies and varied from 15 to 23 (Table 3 ). On the other hand, the chromosomes with the centromere of the $\mathrm{L}$ genome varied from only one (0446022) to nine (066960-2 and 066963-2) (Table 3). There were obviously four type of chromosomes; two 


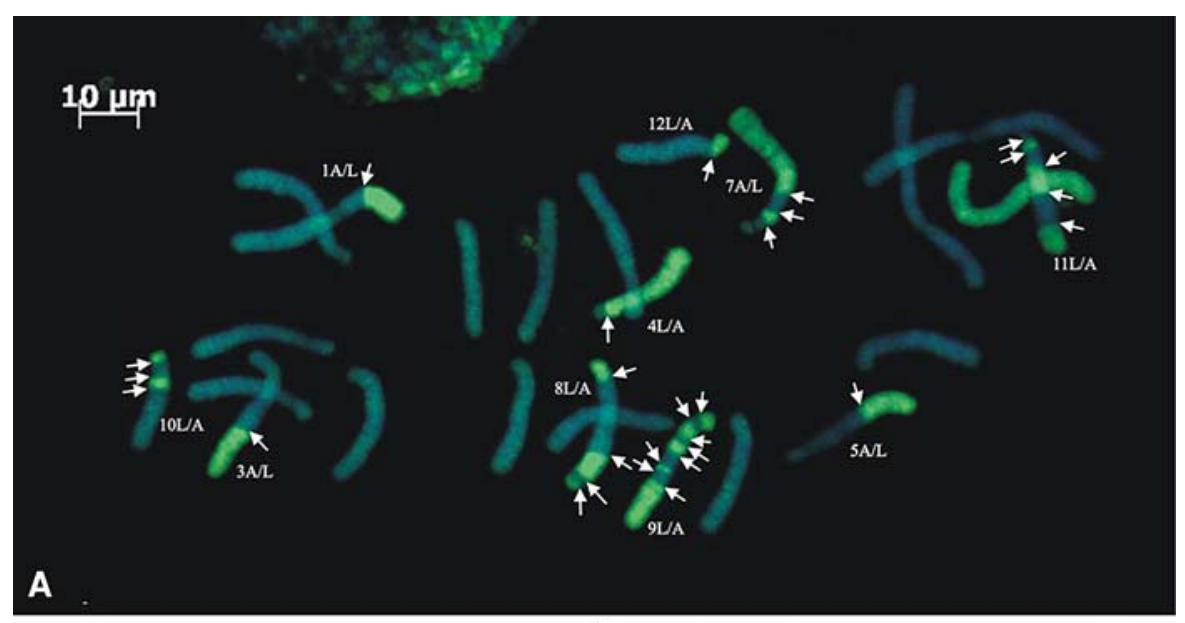

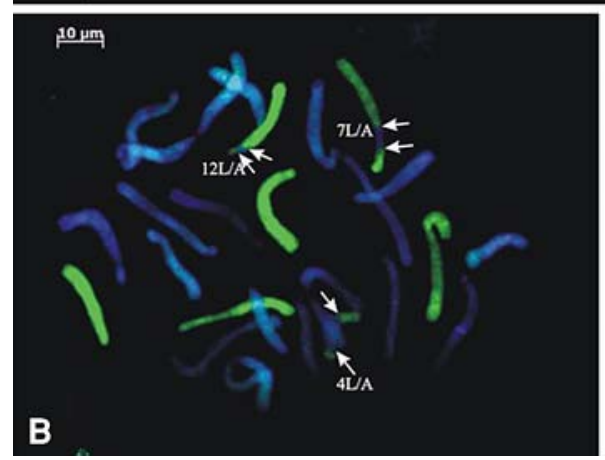

Fig. 1 Chromosome identification and identification of recombination sites with GISH. a and b BC1 LA diploids (044538-2; 066963-7). c BC2 LA diploid (044529-2). Recombinant chromo-

non-recombinant chromosomes, $\mathrm{L}$ and $\mathrm{A}$ and two recombinant chromosomes L/A and A/L. Those with a centromere of Asiatic chromosome with a recombinant segment of Longiflorum, are indicated as $\mathrm{A} / \mathrm{L}$, and vice versa, i.e., L/A (Table 3; Fig. 1a-c). In all, there were $71 \mathrm{~L} / \mathrm{A}$ and $86 \mathrm{~A} / \mathrm{L}$ types of recombinant chromosomes found in the total of progenies analysed. Taking the total length of both $\mathrm{A}$ and $\mathrm{L}$ chromosomes in the $\mathrm{BC} 1$ progenies, the percentages of each genome present in the $\mathrm{BC} 1$ progenies was estimated (Table 3). The percentage of $\mathrm{L}$ genome deviated from the expected $(25 \%)$ and it varied from $3.3 \%(044602-2)$ to as high as $32.5 \%(066960-15)$, nearly a ten fold variation. In order to estimate the number and types of recombinant chromosomes and the lengths of recombinant segments, the karyotypes of some of the $\mathrm{BC} 1$ progenies were determined as shown in Fig. 2. It was found that a considerable amount of Longiflorum genome was transmitted from $\mathrm{LA}$ hybrids to $\mathrm{BC} 1$ progenies, however, the $\mathrm{BC} 2$

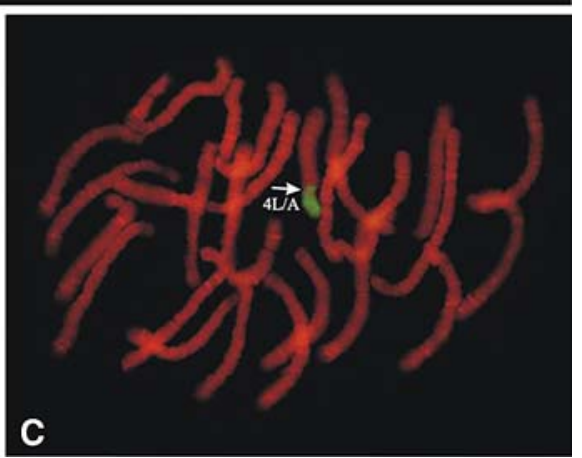

somes are marked with arrow heads indicating both types of recombinant chromosomes either L/A (centromere of Longiflorum genome with Asiatic recombinant segment) or vice versa i.e., $\mathrm{A} / \mathrm{L}$

progenies possessed hardly any of the alien genome or segments of L genome (Fig. 1c).

\section{Discussion}

Nearly $30 \%$ of the $104 \mathrm{BC} 1$ progenies produced from LA hybrids in this investigation turned out to be diploid or near diploid (i.e., aneuploid with almost diploid chromosome count). This shows that there is a prospect for producing sufficient number of diploid $\mathrm{BC} 1$ progenies suitable for analytic breeding in LA hybrids. An attractive feature of these progenies is that it might be possible to monitor the segregation of distinctive genetic traits that distinguish the two parental species. The inheritance patterns of some of the desirable horticultural traits in these progenies might provide an insight into how such traits can be utilized in breeding lilies. Because the generation time of lilies is long (two or more years) the segregation of 
Table 3 Genome composition of BC1 (diploid and aneuploid) LA hybrids and the number of recombinant chromosomes among different genotypes

\begin{tabular}{|c|c|c|c|c|c|c|c|}
\hline \multirow[t]{2}{*}{ Cross } & \multirow[t]{2}{*}{ Genotype code } & \multirow[t]{2}{*}{ Ploidy level } & \multicolumn{2}{|c|}{ Genome composition } & \multicolumn{2}{|c|}{ Genome percentage } & \multirow{2}{*}{$\begin{array}{l}\text { No. of recombinant } \\
\text { chromosomes }\end{array}$} \\
\hline & & & $\mathrm{L}^{(\mathrm{L} / \mathrm{A})}$ & $\mathrm{A}^{(\mathrm{A} / \mathrm{L})}$ & $\mathrm{L}(\%)$ & $\mathrm{A}(\%)$ & \\
\hline LAA & $044511-1$ & $2 x$ & $3(1)$ & $21(2)$ & 12.55 & 87.45 & 3 \\
\hline LAA & $044538-1$ & $2 x$ & $7(7)$ & $17(4)$ & 24.37 & 75.62 & 11 \\
\hline LAA & $044538-2$ & $2 x$ & $7(6)$ & $17(3)$ & 28.6 & 71.4 & 9 \\
\hline LAA & $044538-3$ & $2 x$ & $4(2)$ & $20(4)$ & 17.84 & 82.15 & 6 \\
\hline LAA & $044538-4$ & $2 x$ & $5(2)$ & $19(5)$ & 24.32 & 75.67 & 7 \\
\hline LAA & $062704-2$ & $2 x$ & $4(2)$ & $20(4)$ & 25.6 & 74.63 & 6 \\
\hline LAA & $062704-5$ & $2 x$ & $6(4)$ & $18(4)$ & 16 & 84 & 8 \\
\hline LAA & $065051-3$ & $2 x$ & $3(3)$ & $21(2)$ & 8.81 & 91.18 & 5 \\
\hline LAA & $065051-5$ & $2 x-1$ & $3(2)$ & $20(3)$ & 17.80 & 82.20 & 5 \\
\hline LAA & $065051-6$ & $2 x$ & $7(6)$ & $17(3)$ & 27.5 & 72.5 & 9 \\
\hline LAA & $066828-5$ & $2 x$ & $5(4)$ & $19(2)$ & 15.2 & 84.8 & 6 \\
\hline LAA & $066960-2$ & $2 x$ & $9(5)$ & 15 & 26.88 & 73.11 & 5 \\
\hline LAA & 066960-15 & $2 x+2$ & $7(2)$ & $19(1)$ & 32.52 & 67.47 & 3 \\
\hline LAA & 066960-17 & $2 x$ & $8(4)$ & $16(3)$ & 31.88 & 68.11 & 7 \\
\hline LAA & 066960-22 & $2 x$ & $5(5)$ & $19(4)$ & 13.9 & 86 & 9 \\
\hline LAA & 066963-2 & $2 x$ & $9(5)$ & 15 & 28.9 & 71.09 & 5 \\
\hline LAA & 066963-7 & $2 x$ & $7(3)$ & 17 & 25.2 & 74.8 & 3 \\
\hline LAA & 066994-1 & $2 x$ & $6(3)$ & $18(4)$ & 27.81 & 72.18 & 7 \\
\hline LAA & 066994-2 & $2 x$ & $4(4)$ & $20(5)$ & 29.28 & 70.72 & 9 \\
\hline LAA & 066994-5 & $2 x$ & $7(5)$ & $17(4)$ & 21 & 79 & 9 \\
\hline LAA & 066994-6 & $2 x+3$ & $7(4)$ & $20(4)$ & 35.9 & 64.1 & 8 \\
\hline LAA & 066994-7 & $2 x+3$ & $7(3)$ & $20(4)$ & 24.37 & 75.63 & 7 \\
\hline LAA & 066994-10 & $2 x$ & $6(3)$ & $18(4)$ & 26.2 & 73.8 & 7 \\
\hline ALA & $044602-2$ & $2 x$ & 1(1) & $23(2)$ & 3.34 & 96.66 & 3 \\
\hline
\end{tabular}

Table 4 Genome composition of BC2 (diploid and aneuploid) LA hybrids and the number of recombinant chromosomes among different genotypes analysed by GISH

\begin{tabular}{llllll}
\hline Cross & $\begin{array}{l}\text { Genotype } \\
\text { code }\end{array}$ & $\begin{array}{l}\text { Ploidy } \\
\text { level }\end{array}$ & Genome composition & $\mathrm{A}^{(\mathrm{A} / \mathrm{L})}$ & $\begin{array}{l}\text { No. of recombinant } \\
\text { chromosomes }\end{array}$ \\
\hline ALAA & $044529-2$ & $2 x$ & $1(1)$ & 23 & 1 \\
ALAA & $044529-3$ & $2 x$ & - & 24 & 0 \\
ALAA & $044529-4$ & $2 x$ & - & 24 & 0 \\
ALAA & $044530-1$ & $2 x$ & 1 & $24(1)$ & 1 \\
LAAA & $044634-1$ & $2 x+1$ & & $24(2)$ & 2 \\
\hline
\end{tabular}

traits has not yet been analysed in the present study. Nevertheless, a cursory look at the karyotypes of BC progenies (Fig. 2) does indicate that there is a potential for genetic variation and consequently a possibility for selection at the diploid level. From the point of view of breeding allopolyploid crops, the results of the present investigation are relevant to other ornamental. Just as in Lilium, an important group of tulips, the so called "Darwin Hybrids", have originated from interspecific hybrids between Tulipa gesneriana $\times$ T. fosteriana (Marasek at al. 2006; Marasek and Okazaki 2008). Despite having genetically differentiated 
Fig. 2 Diagrammatic representation of recombinant chromosomes in BC diploid LA hybrid. 044538-2 and 065051-6 (BC1 LAA type hybrids); 044602-2 (BC1 ALA hybrid) and 044529-2 (A LAA BC2 hybrid). In this figure the black colour represents the Longiflorum genome while grey colour represents the Asiatic one
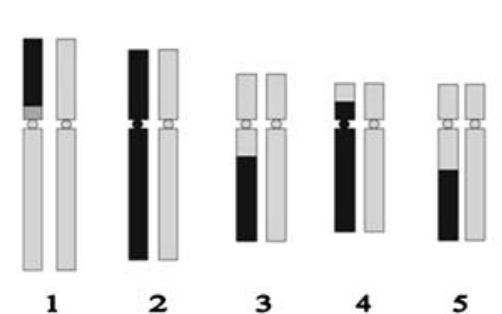

044538-2
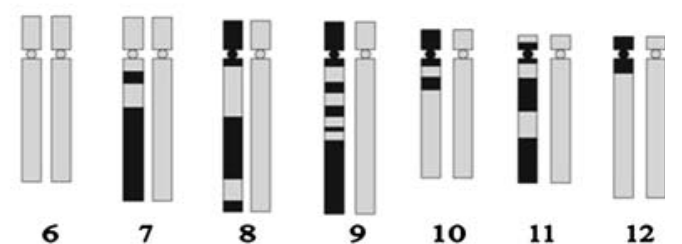

065051-6
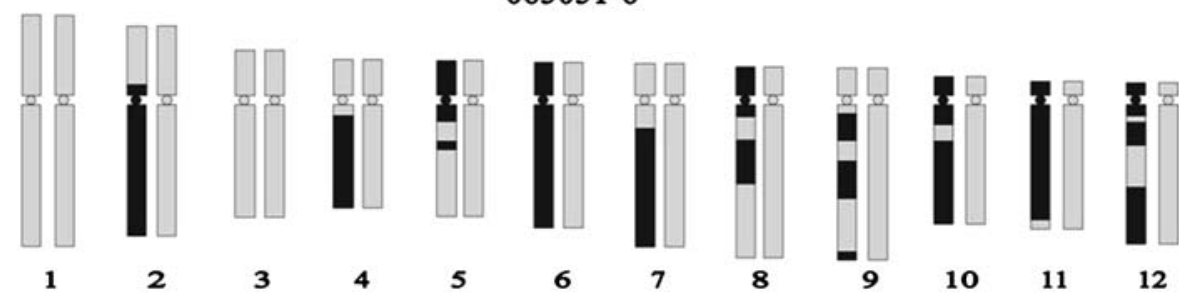

044602-2
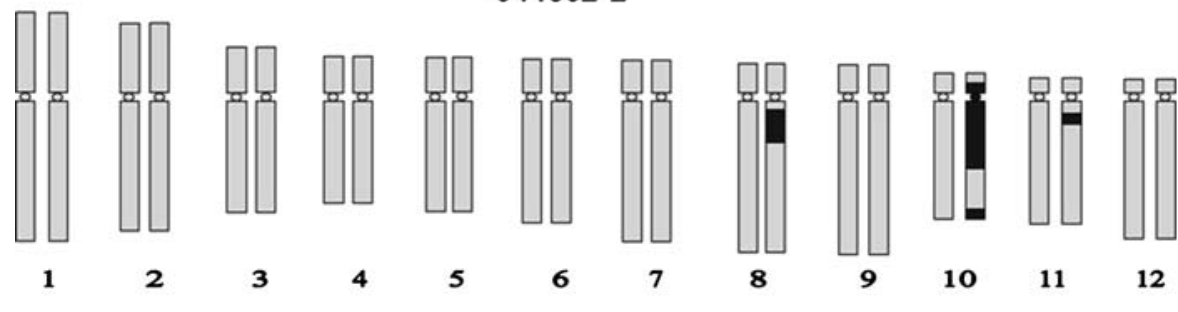

044529-2

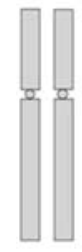

1

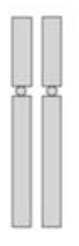

2

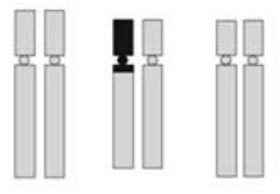

5

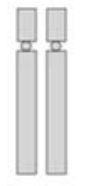

6

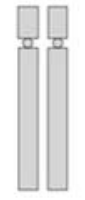

7
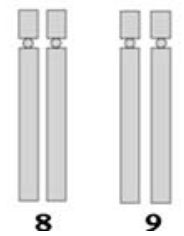

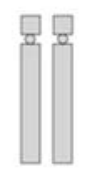

10

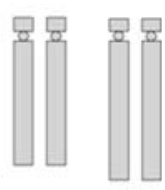

$11 \quad 12$ genomes, these F1 hybrids have been shown to produce both $n$ and $2 n$ gametes so that both diploid $(2 n=$ $2 x=24)$ and triploid $(2 n=3 x=36)$ BC1 progenies can be obtained by backcrossing with one of the parent i.e., T. gesneriana (Marasek and Okazaki 2008).

Similarly, occurrence of both $n$ and $2 n$ gametes has also been reported in other ornamentals like Alstroemeria aurea $\times$ A. inodora (Kamstra at al. 1999). This indicates that there are prospects of using analytic breeding in more ornamental crops other than lily. The potential for genetic variation and consequently the possibility for selection at the diploid level has been practiced in some other crops of economic importance like Lycopersicon esculentum $\times$ Solanum lycopersicoides (Chetelat et al. 1997) and
Festuca $\times$ Lolium (Zwierzykowski et al. 1998; Thomas et al. 2003).

Three important aspects of analytic breeding are, (a) conventional breeding at diploid level for improved quality and high yield traits (b) the maximization of heterozygosity in the polyploids that might be produced from the selected diploid genotypes and (c) introgression of desirable traits from on species to the other. For good reasons, it has been argued that a higher degree of heterozygosity can be achieved at the polyploid rather than at the diploid level (Bingham 1980; Sanford 1983). The reason being that polyploids have a greater probability of possessing three or more different alleles at the same locus whereas it is restricted to only two in diploids. The importance of 
poly allelic loci for inducing vigour and fertility in autopolyploids has been demonstrated in the case of Medicago sativa (Busbice and Wilsie 1966). This aspect can be verified by using diploid BC progenies for breeding and selection followed by polyploidization in lilies. A hypothetical analytic breeding scheme for lily LA hybrids has been represented in Fig. 3.

The traditional method of introgressing traits into allopolyploids was through the re-synthesis of the crop by using the putative parental species as has been done in Ipomea spp. (Orjeda et al. 1991), AegilopsTriticum (Feldman et al. 1997; Ozkan et al. 2001), Spartina spp. (Baumel et al. 2002), Musa Spp. (Ortiz 1997), and Brassicas (Lukens et al. 2006; Nicolas et al. 2007). Hybridization of such re-synthesized allopolyploid with elite cultivars adds the entire genomes of the alien species rather than only the chromosome segments that possess the desirable traits. The addition of entire genomes, obviously, adds many undesirable traits along with the desirable ones into the cultivars enhancing so called, linkage drag (Hospital 2001). One effective way of preventing linkage drag is to add specific recombinant segments that possess desirable traits (Servin et al. 2004). An important requirement for this is that, (a) homoeologous recombination must be accomplished in the hybrids of the putative parental species and (b) the recombinant chromosomes

\section{Diploid cultivars as source of material}

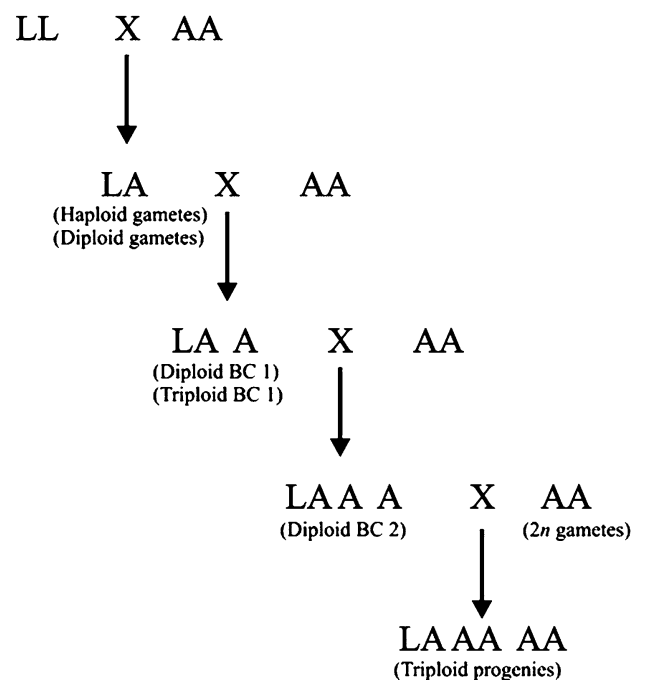

Fig. 3 Hypothetical analytic breeding scheme for LA hybrids, L-Longiflorum genome, A-Asiatic genome must be recovered in the progenies of the F1 hybrids. These two requirements are most ideally achieved in the case of LA hybrids studied here and a wide range of recombinant chromosomes with varying numbers and lengths of recombinant segments have been recovered in the $\mathrm{BC} 1$ progenies (Table 2; Figs. 1a, b and 2). Besides, it has also been possible to produce $\mathrm{BC} 2$ progenies from the triploid $\mathrm{BC} 1$ genotypes (Table 2). In a previous study it was found that in the progenies of $3 x-2 x$ crosses of Longiflorum $\times$ Asiatic and $3 x-2 x$ and reciprocal crosses of Oriental $\times$ Asiatic hybrids lilies, predominantly near diploid (i.e., aneuploid) or diploid progenies occurred indicating that triploid $\mathrm{BC} 1$ plants produced both balanced $n$ as well as near haploid (e.g., $n+1$ or $n+2$ etc.) gametes (Lim et al. 2003; Barba-Gonzalez et al. 2006a). Similarly, present investigation shows that most of the BC2 progenies obtained after $2 x-3 x$ and in reciprocal crosses produced mostly diploid progenies. However, there is no convincing explanation for the occurrence of balanced $n$ gametes in triploids used in the present study. This appears to be genotype dependent that needs to be confirmed by further analysis. Therefore, more progenies from this cross have to be analysed. A notable feature of the $\mathrm{BC} 2$ progenies obtained from $2 x-3 x$ and reciprocal crosses is that they transmit very short recombinant segments or very few alien chromosomes to the progenies. These might be especially favourable in avoiding linkage drag. The scarcity of L genome chromosomes or segments in these $\mathrm{BC} 2$ progenies might have resulted from a process of selection of gametes during fertilization or embryo development or due to non-inclusion of $\mathrm{L}$ genome chromosomes during gamete formation. This implies that introgression of some desirable Longiflorum traits into an Asiatic cultivar could be realized at BC2 level. Similar results have been found in Festuca-Lolium intergeneric hybrids where freezing tolerance genes were successfully introgressed into Lolium multiflorum from Festuca pratensis in a back cross breeding programme (Kosmala et al. 2006).

Besides their relevance to analytic breeding, the diploid $\mathrm{BC}$ progenies can be useful for molecular mapping of useful traits as exampled in other crops like banana (Fauré et al. 1993; Raboin et al. 2005), wheat (Dubcovsky et al. 1996), alfalfa (Barcaccia et al. 1999) and cotton (Desai et al. 2008). Especially when quantitative traits are to be transferred, diploids 
might more conducive for tagging the quantitative loci that might be used in marker assisted selection (Dirlewanger et al. 2004). Diploid BC1 ALA and LAA plants can be backcrossed with the recurrent Asiatic parents to get the genes of interest in backcross progenies. Finally, the concept of hybrid vigour resulting from the degree of heterozygosity of the polyploid progenies can be assessed through the use of molecular methods and the advantages of analytic breeding can be determined.

Open Access This article is distributed under the terms of the Creative Commons Attribution Noncommercial License which permits any noncommercial use, distribution, and reproduction in any medium, provided the original author(s) and source are credited.

\section{References}

Barba-Gonzalez R, Lokker BH, Lim K-B, Ramanna MS, Van Tuyl JM (2004) Use of $2 n$ gametes for the production of sexual polyploids from sterile Oriental $\times$ Asiatic hybrids of lilies (Lilium). Theor Appl Genet 109:1125-1132. doi:10.1007/s00122-004-1739-0

Barba-Gonzalez R, Lim K-B, Ramanna MS, Visser RGF, Van Tuyl JM (2005) The occurrence of intergenomic recombination in the F1 hybrid of Oriental $\times$ Asiatic lily hybrids (Lilium) and its significance for genetic variation in the $\mathrm{BC} 1$ progenies as revealed by GISH and FISH analysis. Genome 48:884-894. doi:10.1139/g05-064

Barba-Gonzalez R, Alex AVS, Visser RGF, Ramanna MS, Van Tuyl JM (2006a) Progenies of allotriploids of Oriental $\times$ Asiatic lilies (Lilium) examined by GISH analysis. Euphytica 151:243-250. doi:10.1007/s10681-006-9148-x

Barba-Gonzalez R, Miller CT, Ramanna MS, Van Tuyl JM (2006b) Induction of $2 n$ gametes for overcoming F1-sterility in lily and tulip. Acta Hortic 714:99-106

Barcaccia G, Albertini E, Tavoletti S, Falcinelli M, Veronesi F (1999) AFLP fingerprinting in Medicago spp.: its development and application in linkage mapping. Plant Breed 118:335-340. doi:10.1046/j.1439-0523.1999.00376.x

Barcaccia G, Albertini E, Rosellini D, Tavoletti S, Veronesi F (2000) Inheritance and mapping of $2 n$ egg production in diploid alfalfa. Genome 43:528-537. doi:10.1139/gen-43-3-528

Barthes L, Ricroch A (2001) Interspecific chromosomal rearrangements in monosomic addition lines of Allium. Genome 44:929-935. doi:10.1139/gen-44-5-929

Baumel A, Ainouche ML, Kalendar R, Schulman AH (2002) Retrotransposons and genomic stability in populations of the young allopolyploid species Spartina anglica C.E. Hubbard (Poaceae). Mol Biol Evol 19:1218-1227

Bingham ET (1980) Maximising heterozygosity in autopolyploids. In: Lewis WH (ed) Polyploidy-biological relevance. Plenum Press, New York, pp 471-490

Bingham ET, Groose RW, Woodfield DR, Kidwell KK (1994) Complementary gene interactions in alfalfa are greater in autotetraploids than diploids. Crop Sci 34:823-829
Busbice TH, Wilsie CP (1966) Genetics of Medicago sativa L. I. Inheritance of dwarf character, $D w_{1}^{1}$. Crop Sci 6:327-330

Chase SS (1963) Androgenesis-its use for transfer of maize cytoplasm. J Hered 54:152-158

Chetelat RT, Cisneros P, Stamova L, Rick CM (1997) A malefertile Lycopersicon esculentum $\times$ Solanum lycopersicoides hybrid enables direct backcrossing to tomato at the diploid level. Euphytica 95:99-108. doi:10.1023/ A: 1002958030799

Desai A, Chee PW, May OL, Paterson AH (2008) Correspondence of trichome mutations in diploid and tetraploid cottons. J Hered 99:182-186. doi:10.1093/jhered/esm1 12

Dirlewanger E, Graziano E, Joobeur T, Garriga-Calderé F, Cosson P, Howad W et al (2004) Comparative mapping and marker-assisted selection in Rosaceae fruit crops. Proc Natl Acad Sci USA 1013:9891-9896. doi:10.1073/pnas. 0307937101

Dubcovsky J, Luo M-C, Zhong G-Y, Bransteiter R, Desai A, Kilian A et al (1996) Genetic map of diploid wheat, Triticum monococcum L., and its comparison with maps of Hordeum vulgare L. Genetics 143:983-999

Estilai A (1977) Interspecific hybrids between Carthamus tinetorius and C. alexandrinus ${ }^{1}$. Crop Sci 17:800-802

Fauré S, Noyer J-L, Horry JP, Bakry F, Lanaud C, Gonzàlez-deLeón D (1993) A molecular marker-based linkage map of diploid bananas (Musa acuminata). Theor Appl Genet 87:517-526. doi:10.1007/BF00215098

Feldman M, Levy AA (2005) Allopolyploidy—a shaping force in the evolution of wheat genomes. Cytogenet Genome Res 109:250-258. doi:10.1159/000082407

Feldman M, Liu B, Segal G, Abbo S, Levy AA, Vega JM (1997) Rapid elimination of low-copy DNA sequences in polyploid wheat: a possible mechanism for differentiation of homoeologous chromosomes. Genetics 147:1381-1387

Gu XF, Yang AF, Meng H, Zhang JR (2005) In vitro induction of tetraploid plants from diploid Zizyphus jujuba Mill cv. Zhanhua. Plant Cell Rep 24:671-676. doi:10.1007/ s00299-005-0017-1

Hospital F (2001) Size of donor chromosome segments around introgressed loci and reduction of linkage drag in markerassisted backcross programs. Genetics 158:1363-1379

Hoya A, Shibaike H, Morita T, Ito M (2007) Germination characteristics of native Japanese dandelion autopolyploids and their putative diploid parent species. J Plant Res 120:139-147. doi:10.1007/s10265-006-0034-3

Jacobsen E, Ramanna MS, Huigen DJ, Sawor Z (1991) Introduction of an amylose free (amf) mutant into breeding of cultivated potato Solanum tuberosum L. Euphytica 53:247-253. doi:10.1007/BF00023276

Kamstra SA, Kuipers AGJ, De Jeu MJ, Ramanna MS, Jacobsen E (1999) The extent and position of homoeologous recombination in a distant hybrid of Alstroemeria: a molecular cytogenetic assessment of first generation backcross progenies. Chromosoma 108:52-63. doi:10.1007/s0041200 50351

Kosmala A, Zwierzykowski Z, Gasior D, Rapacz M, Zwierzykowska E, Humphreys MW (2006) GISH/FISH mapping of genes for freezing tolerance transferred from Festuca pratensis to Lolium multiflorum. Heredity 96: 243-251. doi:10.1038/sj.hdy.6800787

Lim K-B, Chung J-D, Van Kronenburg BCE, Ramanna MS, De Jong JH, Van Tuyl JM (2000) Introgression of Lilium 
rubellum Baker chromosomes into L. longiflorum Thunb.: a genome painting study of the $\mathrm{F} 1$ hybrid, $\mathrm{BC} 1$ and $\mathrm{BC} 2$ progenies. Chromosome Res 8:119-125. doi:10.1023/ A: 1009290418889

Lim K-B, Ramanna MS, De Jong JH, Jacobsen E, Van Tuyl JM (2001) Indeterminate meiotic restitution (IMR): a novel type of meiotic nuclear restitution mechanism detected in interspecific lily hybrids by GISH. Theor Appl Genet 103:219-230. doi:10.1007/s001220100638

Lim K-B, Ramanna MS, Jacobsen E, Van Tuyl JM (2003) Evaluation of $\mathrm{BC} 2$ progenies derived from $3 x-2 x$ and $3 x-4 x$ crosses of Lilium hybrids: a GISH analysis. Theor Appl Genet 106:568-574

Lopez-Lavalle BLA, Orjeda G (2002) Occurrence and cytological mechanism of $2 n$ pollen formation in a tetraploid accession of Ipomoea batatas (sweet potato). J Hered 93:185-192. doi:10.1093/jhered/93.3.185

Lukens LN, Pires JC, Leon E, Vogelzang R, Oslach L, Osborn $\mathrm{T}$ (2006) Patterns of sequence loss and cytosine methylation within a population of newly resynthesized Brassica napus allopolyploids. Plant Physiol 140:336-348. doi:10. 1104/pp.105.066308

Lyrene PM, Vorsa N, Ballington JR (2003) Polyploidy and sexual polyploidization in the genus Vaccinium. Euphytica 133:27-36. doi:10.1023/A:1025608408727

Marasek A, Okazaki K (2008) Analysis of introgression of Tulipa fosteriana genome into Tulipa gesneriana using GISH and FISH. Euphytica 160:217-230. doi:10.1007/ s10681-007-9539-7

Marasek A, Mizuochi H, Okazaki K (2006) The origin of Darwin hybrid tulips analyzed by flow cytometry, karyotype analyses and genomic in situ hybridization. Euphytica 151:279-290. doi:10.1007/s10681-006-9147-y

Mariani A, Tavoletti S (1992) Gametes with somatic chromosome number in the evolution and breeding of polyploid polysomic species. In: Proc Workshop, Perugia, Tipolithographia Porziuncola-Assisi (PG) Italy, pp 1-103

Mendiburu AO, Peloquin SJ, Mok DWS (1974) Potato breeding with haploids and $2 n$ gametes. In: Kasha KJ (ed) Haploids in higher plants. Guelph University Press, Guelph, pp 249-258

Nicolas SD, Mignon GL, Eber F, Coriton O, Monod H, Clouet $\mathrm{V}$ et al (2007) Homoeologous recombination plays a major role in chromosome rearrangements that occur during meiosis of Brassica napus haploids. Genetics 175:487-503. doi:10.1534/genetics.106.062968

Orjeda G, Freye R, Iwanaga M (1991) Use of Ipomoea trifida germ plasm for sweet potato improvement. 3. Development of $4 x$ interspecific hybrids between Ipomoe batatas (L.) Lam. $(2 n=6 x=90)$ and I. trifida (H.B.K) G. Don. $(2 x=2 x=30)$ as storage-root initiators for wild species. Theor Appl Genet 83:159-163. doi:10.1007/BF00226245

Ortiz R (1997) Occurrence and inheritance of $2 n$ pollen in Musa. Ann Bot (Lond) 79:449-453. doi:10.1006/anbo.1996.0367

Ozkan H, Levy AA, Feldman M (2001) Allopolyploidy-induced rapid genome evolution in the wheat (Aegilops-Triticum) group. Plant Cell 13:1735-1747

Peloquin SJ (1981) Chromosomal and cytoplasmic manipulations. In: Frey K (ed) Plant breeding symposium II. The Iowa State University Press, Iowa, pp 117-150
Raboin L-M, Carreel F, Noyer JL, Baurens FC, Horry JP, Bakry F et al (2005) Diploid ancestors of triploid export banana cultivars: molecular identification of $2 n$ restitution gamete donors and $n$ gamete donors. Mol Breed 16:333-341. doi:10.1007/s11032-005-2452-7

Reeves A, Tear J (2000) MicroMeasure for windows, version 3.3. Free program distributed by the authors over the internet from http://www.colostate.edu/Depts/Biology/ MicroMeasure

Sanford JC (1983) Ploidy manipulations. In: Janick J (ed) Methods in fruit breeding. Perdue University Press, West Lafayette

Servin B, Martin OC, Mézard M, Hospital F (2004) Toward a theory of marker-assisted gene pyramiding. Genetics 168:513-523. doi:10.1534/genetics.103.023358

Stewart RN (1947) The morphology of somatic chromosomes in Lilium. Am J Bot 34:9-26. doi:10.2307/2437190

Thomas HM, Morgan WG, Humphreys MW (2003) Designing grasses with a future-combining the attributes of Lolium and Festuca. Euphytica 133:19-26. doi:10.1023/ A:1025694819031

Van Tuyl JM, Boon E (1997) Variation in DNA-content in the genus Lilium. Acta Hortic 430:829-835

Van Tuyl JM, De Jeu MJ (1997) Methods for overcoming interspecific crossing barriers. In: Shivanna KR, Sawhney VK (eds) Pollen biotechnology for crop production and improvement. Cambridge University Press, Cambridge, pp 273-292

Van Tuyl JM, Lim K-B (2003) Interspecific hybridization and polyploidization as tools in ornamental plant breeding. Acta Hortic 612:13-22

Van Tuyl JM, Van Diën MP, Van Creij MGM, Van Kleinwee TCM, Franken J, Bino RJ (1991) Application of in vitro pollination, ovary culture, ovule culture and embryo rescue for overcoming incongruity barriers in interspecific Lilium crosses. Plant Sci 74:115-126. doi:10.1016/0168-9452(91) 90262-7

Weiss H, Maluszynska J (2000) Chromosomal rearrangement in autotetraploid plants of Arabidopsis thaliana. Hereditas 133:255-261. doi:10.1111/j.1601-5223.2000.00255.x

Zeldin EL, McCown BH (2004) Polyploid breeding and the potential of its use for transgene containment with American cranberry (Vaccinium macrocarpon). Acta Hortic 663: $838-840$

Zhang Z, Dai H, Xiao M, Liu X (2007) In vitro induction of tetraploids in Phlox subulata L. Euphytica 159:59-65. doi:10.1007/s10681-007-9457-8

Zhou S (2007) Intergenomic recombination and introgression breeding in Longiflorum $\times$ Asiatic lilies. $\mathrm{PhD}$ Thesis, University Wageningen, $111 \mathrm{pp}$

Zhou S, Ramanna MS, Visser RGF, Van Tuyl JM (2008) Genome composition of triploid lily cultivars derived from sexual polyploidization of Longiflorum $\times$ Asiatic hybrids (Lilium). Euphytica 160:207-215. doi:10.1007/s10681007-9538-8

Zwierzykowski Z, Tayyar R, Brunell M, Lukaszewski AJ (1998) Genome recombination in intergeneric hybrids between tetraploid Festuca pratensis and Lolium multiflorum. J Hered 89:324-328. doi:10.1093/jhered/89.4.324 